Article

\title{
Systematic Control of Anodic Aluminum Oxide Nanostructures for Enhancing the Superhydrophobicity of 5052 Aluminum Alloy
}

\author{
Chanyoung Jeong ${ }^{*}+{ }^{\dagger}$ and Hyejeong Ji ${ }^{\dagger}$ \\ Department of Advanced Materials Engineering, Dong-eui University, 176 Eomgwang-ro, Busanjin-gu, \\ Busan 47340, Korea \\ * Correspondence: cjeong@deu.ac.kr; Tel.: +82-51-890-2286 \\ + These authors contributed equally to this work as first author.
}

Received: 14 August 2019; Accepted: 28 September 2019; Published: 2 October 2019

check for updates

\begin{abstract}
The recent increased interest in the various applications of superhydrophobic surfaces necessitates investigating ways of how this property can be enhanced further. Thus, this study investigated how superhydrophobic properties can be enhanced through the formation of anodic alumina nanostructures on 5052 aluminum alloy. A multistep anodizing process that alternates two different anodizing modes, mild anodization (MA) and hard anodization (HA), with an intermediate pore-widening $(\mathrm{PW})$ process was employed. Multistep anodization was employed in two different ways: an MA $\rightarrow \mathrm{PW} \rightarrow \mathrm{HA}$ process and an $\mathrm{HA} \rightarrow \mathrm{PW} \rightarrow$ MA process. Both routes were conducted with $\mathrm{PW}$ durations of 40,50, and $60 \mathrm{~min}$. The well-defined nanostructures were coated with a self-assembled monolayer (SAM) of FDTS $(1 \mathrm{H}, 1 \mathrm{H}, 2 \mathrm{H}, 2 \mathrm{H}$-perfluorodecyltrichlorosilane). The contact angle values of water droplets were maximized in the pillar-like nanostructures, as they have a less solid fraction than porous nanostructures. With this, the study demonstrated the formation mechanism of both nanoscale pillar and nanoscale hierarchical structures, the wettability of the superhydrophobic surfaces, and the relationship between PW duration time with wettability and the solid fraction of the superhydrophobic surfaces.
\end{abstract}

Keywords: aluminum alloy; multistep anodization; pore-widening; pillar nanostructure; superhydrophobic surface

\section{Introduction}

As superhydrophobic surfaces have high static contact angles (CA) greater than $150^{\circ}$ with water droplets, they have recently attracted much interest in surface science due to their utility in a range of applications, including self-cleaning, anti-icing, oil-water separation, and anticorrosion processes [1-13]. To create such a surface for these various applications, fabrication techniques for creating micro- and/or nanostructures on surfaces coated with low surface-energy materials must be developed. In recent years, numerous methods have been used to design and fabricate superhydrophobic surfaces for technologies, including solar cells, gas sensors, and biomedical applications [14-16].

As the most abundant metal in the earth, aluminum (Al) and its alloys have been widely used in structural engineering - automotive, aerospace, building, shipment, and machine industries-due to their good thermal and electrical conductivity, low density, excellent strength, and design parameters. However, aluminum alloys have low corrosion resistance that requires surface treatment application [17-19]. Therefore, it is of great scientific significance and industrial value to be able to fabricate functional superhydrophobic surfaces on aluminum alloys.

To construct superhydrophobic surfaces, two kinds of approaches have been suggested: fabricating a hierarchical structure and modifying surface roughness with low surface energy materials $[2,16,20]$. 
The implementation of a superhydrophobic surface on the aluminum surface depends on controlling the surface shape modification and self-assembled monolayer coating. Among the known surface treatment methods, electrochemical anodization processes have been particularly convenient for modifying the surface shape through aluminum alloy surface etching. It is generally known that anodic aluminum oxide (AAO) films consist of hexagonal nanostructures arranged in cylindrical pillars. The nanopore structure of AAO films is defined by the pore diameter $\left(D_{p}\right)$ and interpore distance $\left(D_{\text {int }}\right)$, which can adjust the surface shape by modulating the anodization voltage $[2,21-25]$. The $D_{p}$ of these films can be increased through pore widening, which consists of immersing the sample in a phosphoric acid solution after anodization. There is a similar study that used two-step electrochemical processes to achieve a similar effect of wetting properties on stainless steel surfaces, albeit on stainless steel surfaces [26]. Despite the similarity, the different composition of stainless steel and 5052 aluminum alloy are different, allowing different nanostructures to be shaped during the anodization process.

In this work, we focus on fabricating hierarchical nanostructures on Al 5052 substrates by employing multistep anodization with an intermediate pore-widening (PW) step. Modulating the anodization voltage between mild anodization (MA) at $40 \mathrm{~V}$ and hard anodization (HA) at $80 \mathrm{~V}$, as well as varying the PW duration, can provide optimized superhydrophobic properties. We also investigated the superhydrophobic properties of the hierarchical structure of AAO modified with a self-assembled monolayer coating.

\section{Materials and Methods}

Aluminum alloy plates (Al 5052), measuring $10 \mathrm{~mm} \times 30 \mathrm{~mm}$ and having 1-mm thickness, were used as substrates. Prior to anodization, the substrates were ultrasonically degreased in an acetone and ethanol mixture and finally rinsed with deionized water. They were subsequently electropolished in a perchloric acid and ethanol mixture (1:4 volumetric ratio) under an applied potential of $20 \mathrm{~V}$ for $60 \mathrm{~s}$ to remove irregularities on the surface. The polished aluminum alloy was used for the working electrode (anode), and a platinum electrode was employed as the counter electrode (cathode). The two electrodes were separated by a distance of $5 \mathrm{~cm}$. The first anodization was conducted in a $0.3-\mathrm{M}$ oxalic acid solution at $0{ }^{\circ} \mathrm{C}$ for $6 \mathrm{~h}$. The anodic aluminum oxide (AAO) layer formed by the first anodization step was removed by soaking in an aqueous mixture solution of $1.8 \mathrm{wt}$. \% chromic acid and $6 \mathrm{wt}$. \% phosphoric acid at $65^{\circ} \mathrm{C}$ for $10 \mathrm{~h}[27,28]$. Then, the same conditions as used in the first anodizing step were applied to the second anodizing step. The second anodizing step involved both the mild anodization (MA) and hard anodization (HA) modes. The MA mode was applied at $40 \mathrm{~V}$ for $30 \mathrm{~min}$, and the HA mode was applied at $80 \mathrm{~V}$ for $30 \mathrm{~s}$ [24]. Anodization was carried out in a constant voltage using a DC power supply with the size of aluminum dipping into the electrolyte. To make the pores wider, the AAO layers were dissolved in $0.1 \mathrm{M}$ phosphoric acid at $30^{\circ} \mathrm{C}$ for various immersion times: 40,50, and $60 \mathrm{~min}$. The same conditions used in the second anodizing step were applied to a third anodizing step to attempt the fabrication of hierarchical nanostructures (see Table 1).

Table 1. Fabrication process conditions for multistep anodization. HA: hard anodization, MA: mild anodization, PW: pore widening.

\begin{tabular}{ccccccccc}
\hline \multirow{2}{*}{ Sample } & First Anodization & AAO Removal & \multicolumn{2}{c}{ Second Anodization } & Pore Widening & \multicolumn{2}{c}{ Third Anodization } \\
\cline { 2 - 8 } & Time (hour) & Time (hour) & Step & Time (min.) & Time (min.) & Step & Time (min.) \\
\hline A & 6 & 10 & MA & 30 & 40 & HA & 0.5 \\
\hline B & 6 & 10 & MA & 30 & 50 & HA & HA & 0.5 \\
\hline C & 6 & 10 & MA & 30 & 60 & 40 & MA & 30 \\
\hline D & 6 & 10 & HA & 0.5 & 0.5 & 50 & MA & MA \\
\hline E & 6 & 10 & HA & HA & 0.5 & 60 & 30 \\
\hline F & 6 & 10 & HA &
\end{tabular}


To make a superhydrophobic AAO surface, the fabricated AAO surfaces were coated with a self-assembled monolayer (SAM) of FDTS $(1 \mathrm{H}, 1 \mathrm{H}, 2 \mathrm{H}, 2 \mathrm{H}$-perfluorodecyltrichlorosilane). Before coating, the samples were cleaned with $\mathrm{O}_{2}$ plasma for $15 \mathrm{~min}$ to remove organic residues and make the surfaces hydrophilic, and were then dried in the air and baked at $150{ }^{\circ} \mathrm{C}$ for $10 \mathrm{~min}$. Then, the tsamples were coated with FDTS for $24 \mathrm{~h}$ in vacuum. For the examination of surface hydrophobicity after SAM coating, static contact angles were measured with a contact angle meter at room temperature. All the measurements were performed at five positions on each sample with a sessile droplet $(\sim 3.5 \mu \mathrm{L})$ of deionized water. The surface morphology of the samples was observed by a field emission scanning electron microscope (FE-SEM).

\section{Results and Discussion}

\subsection{Fabrication Approach}

Anodization has been increasingly used for making various porous nanostructures on aluminum substrates [29-31]. Control of the pore parameters, comprised of $D_{p}$ and $D_{\text {int }}$, is achieved by modulating anodization conditions such as voltage, temperature, and concentration. Anodization voltage, in particular, is the main determinant of $D_{p}$ and $D_{\text {int }}$. For example, compared to the MA mode, the HA mode uses relatively high applied voltage during anodization, which creates larger pore sizes [24]. In addition, if a PW step is performed with anodization, the range of pore sizes that can be obtained is extended. Figure 1 schematically shows the fabrication procedure for hierarchical structures using multistep anodization.

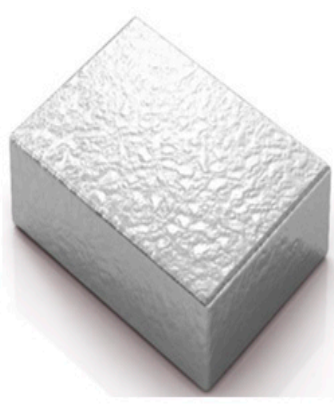

(a)

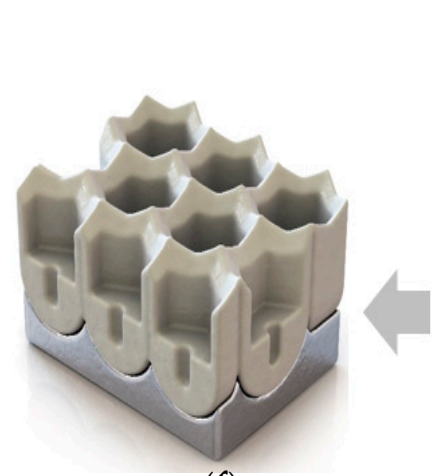

(f)

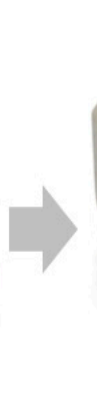

(f)

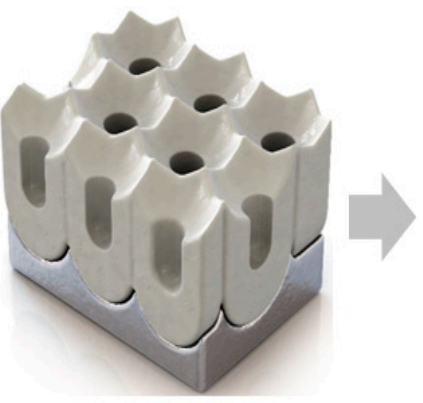

(b)

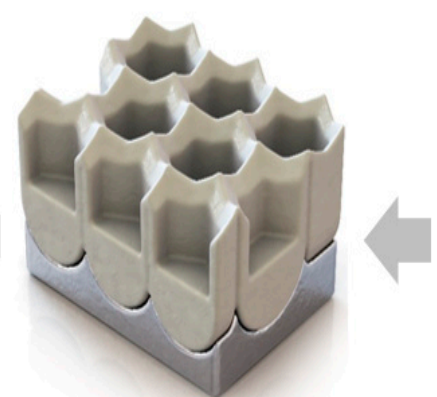

(e)

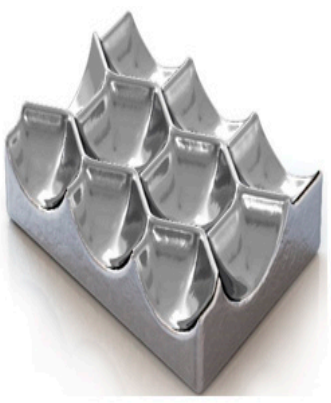

(c)

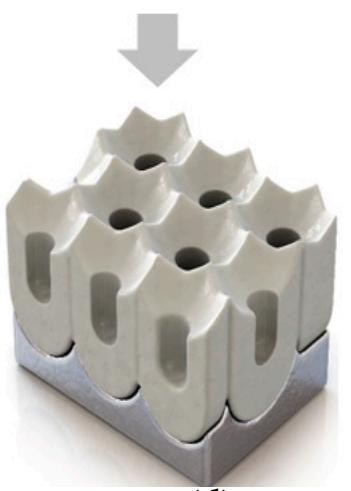

(d)

Figure 1. Schematic of the fabrication of a hierarchical anodic aluminum oxide (AAO) structure through multistep anodization; (a) Electropolished aluminum 5052; (b) First anodization; (c) Remove anodic aluminum oxide; (d) Second anodization; (e) Pore-widening; and (f) Third anodization.

First, an Al 5052 sheet is electropolished to obtain a smooth surface. The electropolished Al 5052 is anodized in oxalic acid to fabricate an initial nanoporous alumina layer in the first anodization. Then, this nanopore layer is removed by chemical etching for the second anodization, in which the 
alumina is anodized again to fabricate a new AAO film under different anodization conditions (i.e., MA and HA steps). Then, this porous nanostructure is widened in phosphoric solution with different durations. Finally, in the third anodization, porous alumina is anodized to fabricate a distinctly different structure using the same conditions as the second anodization step. The different values of $D_{p}$ and $D_{i n t}$ that result from variations in the anodization voltage applied during the second and third anodization steps and during the pore-widening (PW) duration employed between these steps produce a hierarchical structure.

\subsection{Effect of the Voltage Morphology}

The study investigated the effect of anodization voltage under a fixed PW time (40 min). FE-SEM images of the electropolished Al 5052 surfaces were subjected to either an MA $\rightarrow$ PW $\rightarrow$ HA process or an $\mathrm{HA} \rightarrow \mathrm{PW} \rightarrow$ MA process, as shown in Figures 2 and 3, respectively.

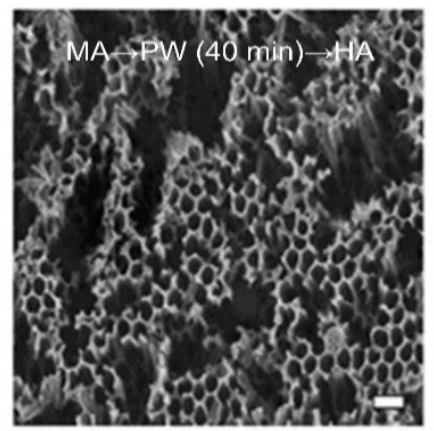

(a)

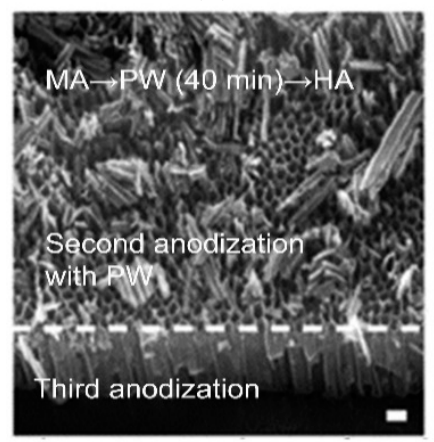

(d)

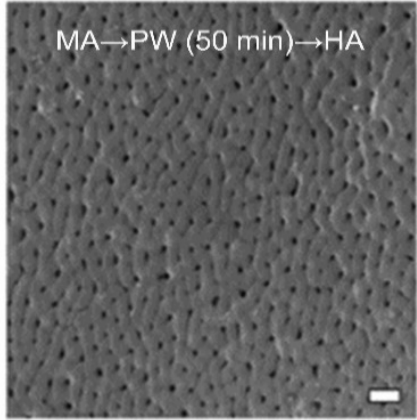

(b)

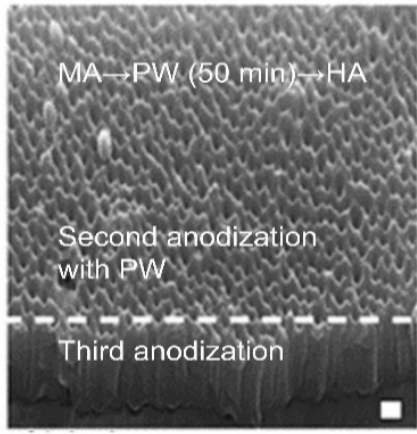

(e)

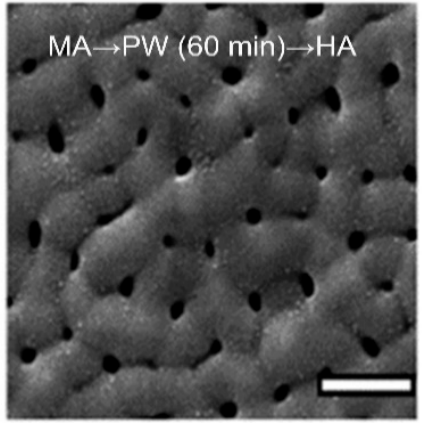

(c)

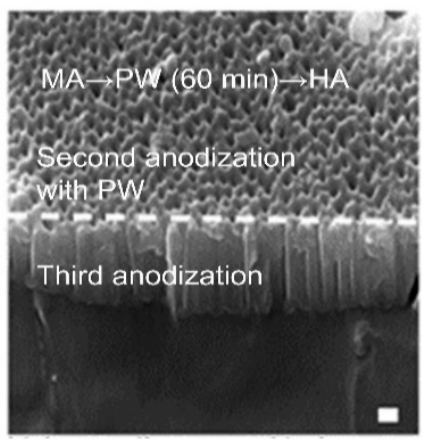

(f)

Figure 2. FE-SEM images of AAO for the MA $\rightarrow \mathrm{PW} \rightarrow \mathrm{HA}$ fabrication step with an intermediate pore-widening duration of (a) to (c) (a,d) $40 \mathrm{~min}$ (Sample A), (b,e) $50 \mathrm{~min}$ (Sample B), and (c,f) $60 \mathrm{~min}$ (Sample C). Figures (a) to (c) shows the top view, while (d) to (f) shows the cross-section. Scale bar $=200 \mathrm{~nm}$. 


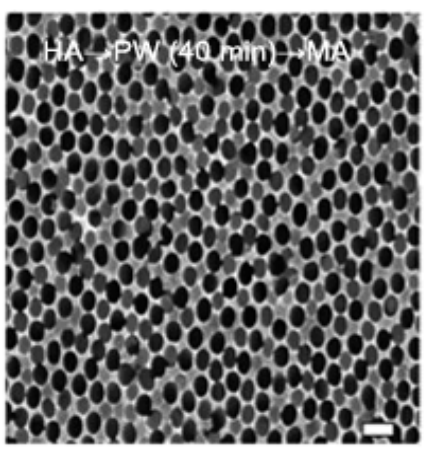

(a)

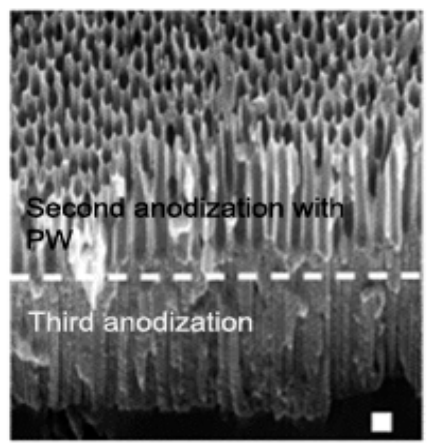

(d)

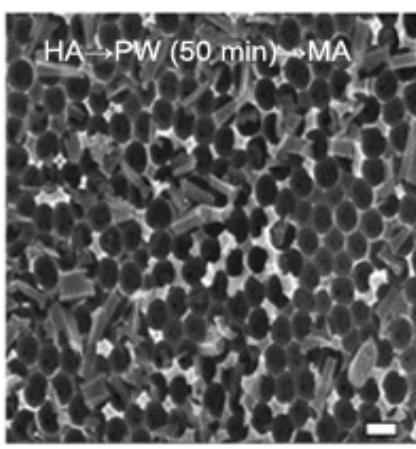

(b)

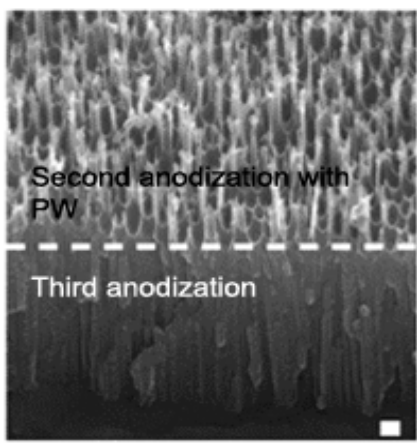

(e)

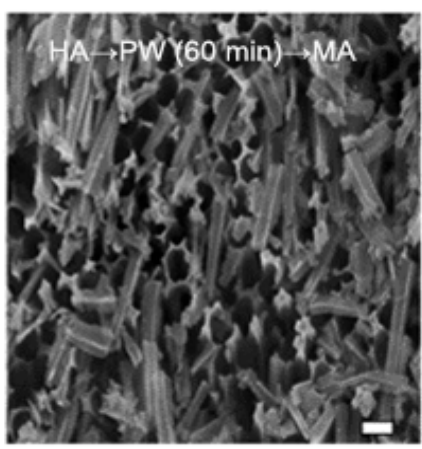

(c)

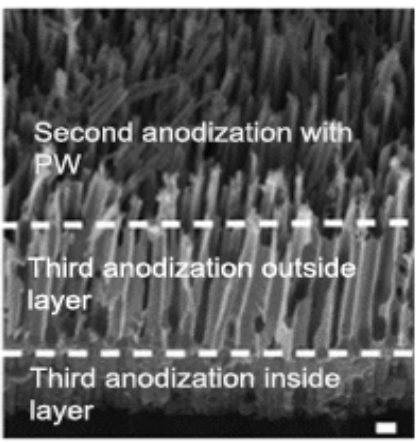

(f)

Figure 3. FE-SEM images of AAO for the fabricating the $\mathrm{HA} \rightarrow \mathrm{PW} \rightarrow \mathrm{MA}$ step with an intermediate pore-widening duration of (a,d) $40 \mathrm{~min}$ (Sample D), (b,e) $50 \mathrm{~min}$ (Sample E), and (c,f) $60 \mathrm{~min}$ (Sample F). a-c shows the top view, while $\mathbf{d}-\mathbf{f}$ shows the cross-section. Scale bar $=200 \mathrm{~nm}$.

Different pore diameters and interpore distances derived from the applied anodization voltage employed were observed depending on whether the MA or HA step was applied first. Table 2 presents the average values of $D_{p}$ and $D_{\text {int }}$. The values of $D_{p}$ and $D_{\text {int }}$ were investigated in the cross-sectional images.

Table 2. Characterization of the AAO structures on 5052 aluminum alloy.

\begin{tabular}{cccccccc}
\hline \multirow{2}{*}{ Sample } & $\begin{array}{c}\text { Second } \\
\text { Anodization Step }\end{array}$ & Pore Widening & $\begin{array}{c}\text { Third Anodization } \\
\text { Step }\end{array}$ & $\begin{array}{c}\text { Second Anodization Region } \\
\text { with PW }\end{array}$ & \multicolumn{2}{c}{$\begin{array}{c}\text { Third Anodization } \\
\text { Region }\end{array}$} \\
\cline { 2 - 8 } & Type & Time (min.) & Type & $\mathbf{D}_{\mathbf{p}}(\mathbf{n m})$ & $\mathbf{D}_{\text {int }}(\mathbf{n m})$ & $\mathbf{D}_{\mathbf{p}}(\mathbf{n m})$ & $\mathbf{D}_{\text {int }}(\mathbf{n m})$ \\
\hline A & MA & 40 & HA & $85 \pm 1.9$ & $100 \pm 1.7$ & $30 \pm 5.2$ & $115 \pm 9.5$ \\
\hline B & MA & 50 & HA & None & None & $31 \pm 2.2$ & $182 \pm 22$ \\
\hline C & MA & 60 & HA & None & None & $33 \pm 2.5$ & $219 \pm 38$ \\
\hline D & HA & 40 & MA & $95 \pm 4.5$ & $137 \pm 7.3$ & $19 \pm 1.5$ & $94 \pm 1.8$ \\
\hline E & HA & 50 & MA & $134 \pm 3.2$ & $185 \pm 78$ & $18 \pm 1.8$ & $90 \pm 6.3$ \\
\hline F & HA & 60 & MA & None & None & $135 \pm 4.3$ & $182 \pm 7.3$ \\
\hline & & & & & & & \\
\hline
\end{tabular}

For the samples fabricated using either the MA $\rightarrow \mathrm{PW} \rightarrow \mathrm{HA}$ or the $\mathrm{HA} \rightarrow \mathrm{PW} \rightarrow$ MA process, the anodization and PW parameters (i.e., electrolyte used, temperature, and concentration) are constant. Figure $2 \mathrm{~d}$ shows the FE-SEM image of the AAO after MA $\rightarrow$ PW $\rightarrow$ HA anodization. The MA of the second anodization resulted in $D_{p}=85$ and $D_{\text {int }}=100$. After a $40-$ min PW step, the HA of the third anodization resulted in $D_{p}=30 \mathrm{~nm}$ and $D_{\text {int }}=115 \mathrm{~nm}$ (Sample A). The structural morphology created by the 40-min PW process for dissolving the cell wall exhibited a pillar structure consisting of a combination of collapsing and individually standing pillars. Figure $3 \mathrm{~d}$ shows the FE-SEM image of the AAO that underwent the reverse process: $\mathrm{HA} \rightarrow \mathrm{PW} \rightarrow \mathrm{MA}$. The HA results of the second anodization were $D_{p}=95 \mathrm{~nm}$ and $D_{\text {int }}=137 \mathrm{~nm}$. After the PW step, the MA results of the third 
anodization were $D_{p}=19 \mathrm{~nm}$ and $D_{\text {int }}=94 \mathrm{~nm}$ (Sample D). The $D_{p}$ and $D_{\text {int }}$ values for the MA $\rightarrow$ $\mathrm{PW} \rightarrow \mathrm{HA}$ process were greater than those resulting from the $\mathrm{HA} \rightarrow \mathrm{PW} \rightarrow$ MA process. The results suggest that hierarchical structures can be fabricated by modulating the anodization voltages, and that the PW step influences both $D_{p}$ and $D_{\text {int }}$ of the second anodization region, but not of the third anodization region. It is generally accepted that the $D_{p}$ and $D_{\text {int }}$ of a porous nanostructure can be adjusted by anodization conditions such as the electrolyte type, anodization voltage, current density, and temperature. According to the following equations, $D_{p}$ and $D_{\text {int }}$ are dependent on the anodization voltage [32,33]:

$$
\begin{gathered}
D_{P}=\lambda_{P} \times U, \\
D_{\text {int }}=\lambda_{\text {int }} \times U
\end{gathered}
$$

where $D_{p}$ is the pore diameter $(\mathrm{nm}), \lambda_{p}$ is a proportionality constant approximately equal to $1.29 \mathrm{~nm} / \mathrm{V}$, $D_{\text {int }}$ is the interpore distance $(\mathrm{nm}), \lambda_{\text {int }}$ is a proportionality constant approximately equal to $2.5 \mathrm{~nm} / \mathrm{V}$, and $\mathrm{U}$ denotes an anodization voltage. From these relationships, it is apparent that a higher applied voltage results in greater values for both $D_{p}$ and $D_{i n t}$. However, it can be confirmed in this case that the values of $D_{p}$ and $D_{\text {int }}$ are both small. Aluminum ions from the aluminum alloy dissolve and form AAO after oxidation during anodization [34]. It is expected that impurities in 5052 aluminum alloy will limit the oxidation reaction during anodization. Despite the same HA conditions, the $\mathrm{D}_{\mathrm{p}}$ resulting from HA used in the second anodization is greater than the $D_{p}$ resulting from HA used in the third anodization, as shown in Table 2. This difference is due to the influence of the PW step after the second anodization. Therefore, a porous hierarchical nanostructure can be fabricated with various sizes of $D_{p}$ and $\mathrm{D}_{\text {int }}$ and different shapes by employing an anodization voltage between the MA and HA steps.

\subsection{Effect of Pore-Widening Time on Morphology}

This study investigated the impact of PW duration under alternative anodization processes such as multistep MA and HA. Figure 2 shows the FE-SEM images of the MA $\rightarrow \mathrm{PW} \rightarrow \mathrm{HA}$ sequence fabricated by controlling the two types of anodization voltage and the intermediate different PW duration. Subsequently, FE-SEM images of the HA $\rightarrow$ PW $\rightarrow$ MA processes through stepwise anodization display the effects of the MA and HA sequences and processes in the intermediate PW step (see Figure 3). To study the effect of the PW duration, the PW time was varied from $40 \mathrm{~min}$ to $60 \mathrm{~min}$. Table 2 shows the average values of $D_{p}$ and $D_{\text {int }}$ for each anodization sequence. For the samples with $\mathrm{MA} \rightarrow \mathrm{PW} \rightarrow \mathrm{HA}$ and $\mathrm{HA} \rightarrow \mathrm{PW} \rightarrow \mathrm{MA}$, the anodization parameters, temperature, electrolyte, and concentration are constant. In the case of the MA $\rightarrow$ PW $\rightarrow$ HA process, a PW time of 40 min exhibits a hybrid structure in the second anodization region. In particular, the AAO structure of the second anodization region completely disappeared after a $40 \mathrm{~min}$ PW duration. Furthermore, a $40 \mathrm{~min}$ PW did not cause a structural change in the third anodization region. PW durations of 50 and $60 \mathrm{~min}$ resulted in $D_{p}=31 \mathrm{~nm}$ and $33 \mathrm{~nm}$, respectively, and $D_{\text {int }}=182$ and $219 \mathrm{~nm}$, respectively, in the third anodization region. Therefore, as the PW time increases, $D_{p}$ and $D_{i n t}$ increase during the third anodization as a result of the AAO dissolution from the second anodization region. It can be seen that PW in phosphoric acid accelerates the dissolution of AAO during the third anodization for the $\mathrm{MA} \rightarrow \mathrm{PW} \rightarrow$ HA process (samples A, B, and C).

In the case of the $\mathrm{HA} \rightarrow \mathrm{PW} \rightarrow$ MA process, the values of $\mathrm{D}_{\mathrm{p}}$ in the second anodization region are $95 \mathrm{~nm}$ and $134 \mathrm{~nm}$ as the PW time increases from $40 \mathrm{~min}$ to $50 \mathrm{~min}$, respectively. When the PW time continuously increases to $60 \mathrm{~min}$, it was observed that the structure in the second anodization region was etched away. $D_{\text {int }}$ in the second anodization region shows a similar trend. On the other hand, $D_{p}$ and $D_{\text {int }}$ in the third anodization region did not show significant differences for PW times of $40 \mathrm{~min}$ and $50 \mathrm{~min}$. However, a $60 \mathrm{~min}$ PW time resulted in a hierarchical structure during the third anodization. The upper bounds of $D_{p}$ and $D_{\text {int }}$ in the third anodization region were found to be $135 \mathrm{~nm}$ and $182 \mathrm{~nm}$, respectively. The lower bounds of $D_{p}$ and $D_{i n t}$ in the third anodization region were found to be $16 \mathrm{~nm}$ and $99 \mathrm{~nm}$, respectively (Samples D, E, and F). The AAO outer layer grew 
during the second anodization, while the AAO inner layer close to the substrate grew during the third anodization [23].

\subsection{Effect of Multistep Anodization on Wettability}

The wettability of the samples was assessed by measuring the static contact angle (CA) (see Table 3).

Table 3. Average contact angle values after FDTS coating. FDTS: $1 \mathrm{H}, 1 \mathrm{H}$, $2 \mathrm{H}, 2 \mathrm{H}$-perfluorodecyltrichlorosilane.

\begin{tabular}{ccc}
\hline Sample & Contact Angle (Distilled Water) $\left(^{\circ}\right)$ & Deviation $\left(^{\circ}\right)$ \\
\hline Control & 114.8 & 0.31 \\
A & 162.0 & 2.04 \\
B & 142.1 & 0.55 \\
C & 126.1 & 0.27 \\
D & 149.2 & 0.78 \\
E & 161.7 & 0.56 \\
F & 166.8 & 1.09
\end{tabular}

Multistep anodization process with intermediate PW; Control: Electropolished Al 5052; Sample A: MA $\rightarrow$ PW $(40 \mathrm{~min}) \rightarrow$ HA; Sample B: MA $\rightarrow$ PW $(50 \mathrm{~min}) \rightarrow$ HA; Sample C: MA $\rightarrow$ PW (60 min) $\rightarrow$ HA; Sample D: HA $\rightarrow$ PW $(40 \mathrm{~min}) \rightarrow$ MA; Sample E: HA $\rightarrow$ PW (50 min $) \rightarrow$ MA; Sample F: HA $\rightarrow$ PW $(60 \mathrm{~min}) \rightarrow$ MA.

Figures 4 and 5 show the contact angle measurement on the hierarchical AAO nanostructures fabricated under the multistep anodization process with PW and coated with FDTS (surface energy: $5 \mathrm{~mJ} / \mathrm{m}^{2}$ ). It is evident that for all anodization processes and PW durations, the contact angle values of the samples were increased compared to that of an untreated aluminum alloy surface.

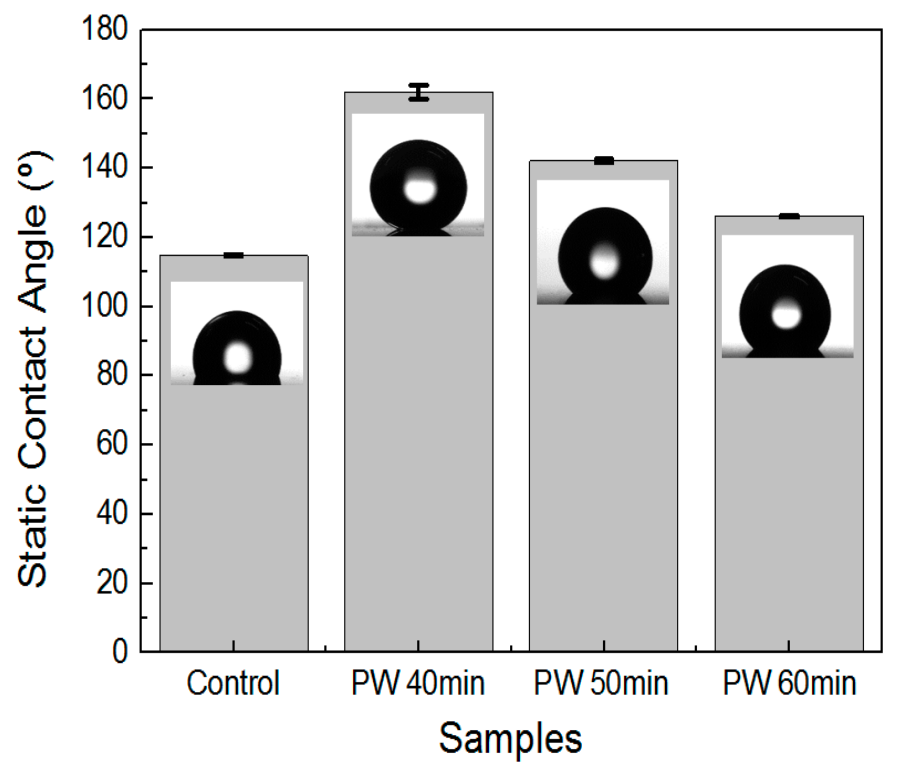

Figure 4. Contact angle measurements on the $\mathrm{AAO}$ fabricated with the $\mathrm{MA} \rightarrow \mathrm{PW} \rightarrow \mathrm{HA}$ process with different PW durations and coated with FTDS. 


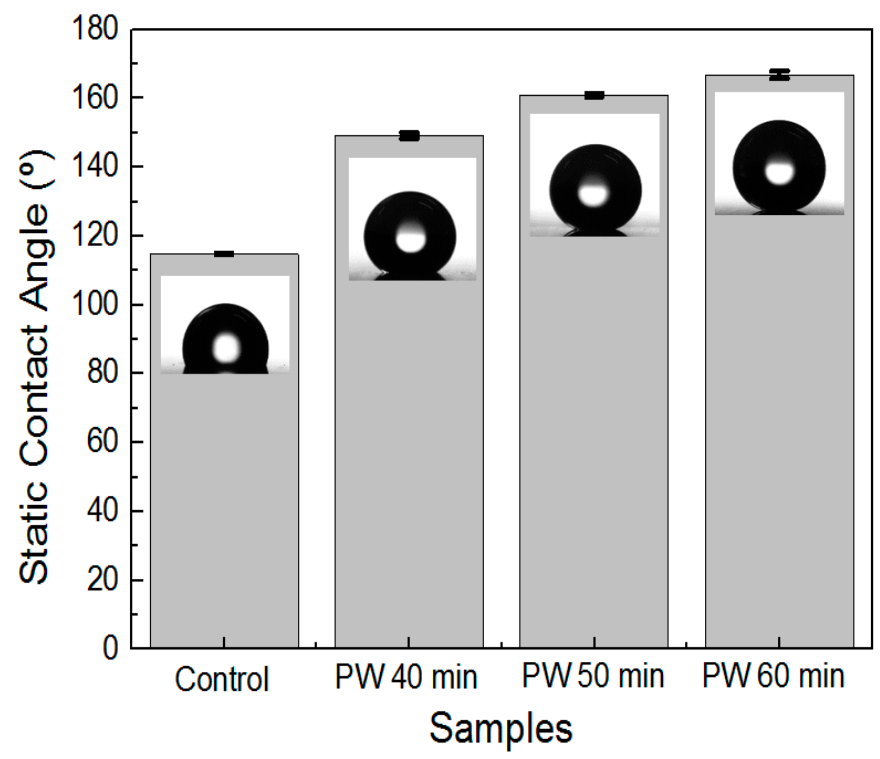

Figure 5. Contact angle measurements on the AAO fabricated with the $\mathrm{HA} \rightarrow \mathrm{PW} \rightarrow$ MA process with different PW times and coated with FTDS.

Figure 4 shows the contact angle measurement of AAO that underwent the MA $\rightarrow \mathrm{PW} \rightarrow \mathrm{HA}$ process with different $\mathrm{PW}$ times. In the case of the MA $\rightarrow \mathrm{PW} \rightarrow \mathrm{HA}$ process, it was found that a hierarchical nanostructure was most significantly obtainable with a PW time of $40 \mathrm{~min}$ (Figure 2d), and this sample exhibited superhydrophobicity. The water droplets formed an almost spherical shape on the AAO surface, with an average CA value of $162.0 \pm 2.04^{\circ}$. When the PW time was 50 and $60 \mathrm{~min}$, the CA values were $142.1 \pm 0.55^{\circ}$ and $126.1 \pm 0.27^{\circ}$, respectively.

Surface energy and surface roughness are the dominant factors in deciding the hydrophobic properties of a superhydrophobic surface. Thus, the lower the surface energy is, the higher the hydrophobicity will be. However, the FDTS (surface energy: $6.7 \mathrm{~mJ} / \mathrm{m}^{2}$ ) can only provide an apparent contact angle of $119^{\circ}$ [35]. Therefore, enhancement of the surface roughness is required to obtain the highest hydrophobicity [36,37]. Considering the Cassie-Baxter wetting state [38], where air is trapped within pores or between solid and liquid interfaces, the static contact angle $(\theta)$ can be described by:

$$
\begin{gathered}
\cos \theta=r_{f} f_{S L} \cos \theta_{0}-1+f_{S L} \\
f_{S L}=1-\frac{2 \pi}{\sqrt{3}} \frac{r^{2}}{\mathrm{a}^{2}}
\end{gathered}
$$

where $\theta_{0}$ is Young's contact angle on a smooth surface, $f_{S L}$ is the fraction of the solid-liquid wet surface (defined as the ratio of the actual area of liquid-solid contact to the projected area), and $r_{f}$ is the roughness of the wetted solid surface (where unity denotes a chemically homogeneous surface). From Equations (3) and (4), it can be found that smaller values of $f_{S L}$ result in greater contact angles on a superhydrophobic surface. The pillar structures of AAO can effectively enhance $r_{f}$ and reduce $f_{S L}$. The structural features (pore diameter, interpore distance, and solid fraction) were summarized in Table 4. The higher solid fraction indicated that the contact angle is a greater value in each process $(\mathrm{MA} \rightarrow \mathrm{PW} \rightarrow \mathrm{HA}$ and $\mathrm{HA} \rightarrow \mathrm{PW} \rightarrow \mathrm{MA}$ ). That is, the AAO morphology plays an important role in determining the characteristics of a hydrophobic surface. This demonstrates that a hybrid structure with a pillar structure can lower the solid fraction and thus significantly enhance the superhydrophobicity. 
Table 4. The structural characteristics of the FDTS-coated AAO nanostructures.

\begin{tabular}{cccc}
\hline Sample & Pore Diameter $(\mathbf{n m})$ & Interpore Distance $(\mathbf{n m})$ & Solid Fraction \\
\hline A & $85 \pm 1.9$ & $100 \pm 1.7$ & $0.348 \pm 0.007$ \\
B & $31 \pm 2.2$ & $182 \pm 22$ & $0.973 \pm 0.003$ \\
C & $33 \pm 2.5$ & $219 \pm 38$ & $0.978 \pm 0.004$ \\
D & $95 \pm 4.5$ & $137 \pm 7.3$ & $0.564 \pm 0.005$ \\
E & $134 \pm 3.2$ & $185 \pm 78$ & $0.524 \pm 0.997$ \\
F & $135 \pm 4.3$ & $182 \pm 7.3$ & $0.496 \pm 0.072$ \\
\hline
\end{tabular}

Figure 5 shows the contact angle measurement of AAO that underwent the $\mathrm{HA} \rightarrow \mathrm{PW} \rightarrow \mathrm{MA}$ process with different $\mathrm{PW}$ times. In this case, increasing the PW time increased the effectiveness of the pillar nanostructures (Figure 3d-f). The average CA value for a PW time of $40 \mathrm{~min}$ was $149.2 \pm 0.78^{\circ}$. As the PW time reached $50 \mathrm{~min}$, the sample exhibited superhydrophobicity. The water droplets formed an almost spherical shape on the AAO surface, with an average CA value of $161.7 \pm 0.56^{\circ}$. When the PW time was increased to $60 \mathrm{~min}$, the water droplets attained an even more spherical shape on the AAO surface, with CA values as high as $166.8 \pm 1.09^{\circ}$. These CA values reveal that with given low surface energy, the surface wettability of both hierarchical and pillar AAO is affected by the surface shape and roughness. Therefore, the above results demonstrate that the pillar hierarchical structure of AAO with a less solid faction displayed the largest superhydrophobic surface.

\section{Conclusions}

This paper demonstrated the successful fabrication of both hierarchical and pillar-like AAO nanostructures on 5052 aluminum alloy using multistep anodization and a PW process. In particular, different anodization voltages were applied alternately to fabricate the hierarchical structures. Typically, the pillar structure does not show a unified AAO produced under the MA $\rightarrow \mathrm{PW} \rightarrow \mathrm{HA}$ conditions, due to difficulty in producing more uniform pillar-like nanostructures than pure aluminum. However, a uniform pillar nanostructure under the HA $\rightarrow \mathrm{PW} \rightarrow$ MA condition was successfully demonstrated.

Pillar AAO nanostructures created through multistep anodization significantly enhanced the surface roughness. After a hydrophobic coating, the tip-like structure of AAO exhibited superior superhydrophobic efficiency with a high contact angle $\left(<166^{\circ}\right)$. Through a process for adjusting the surface shape, more air can be trapped inside the nanoscale pore structure, resulting in enhanced superhydrophobic properties. The hybrid nanostructures such as pillars created by anodization not only improve hydrophobicity, but are also inexpensive and easy to produce, which will greatly benefit industrial and engineering applications.

Author Contributions: Conceptualization, C.J.; Experimentation and data collection, C.J. and H.J.; Formal analysis, C.J. and H.J.; Draft, C.J. and H.J.; Revision and review, C.J. All authors read and approved the final manuscript.

Funding: This research was funded by the Basic Science Research Program of the National Research Foundation of Korea (NRF), grant number NRF-2017R1C1B5075577.

Conflicts of Interest: The authors declare no conflict of interest.

\section{Abbreviations}

AAO: anodic aluminum oxide; $\mathrm{D}_{\mathrm{p}}$ : pore diameter; $\mathrm{D}_{\text {int }}$ : interpore distance; $\mathrm{PW}$ : pore-widening; MA: mild anodization; HA: hard anodization.

\section{References}

1. Blossey, R. Self-cleaning surfaces-Virtual realities. Nat. Mater. 2003, 5, 301-306. [CrossRef] [PubMed]

2. Jeong, C.; Choi, C.H. Single-step direct fabrication of pillar-on-pore hybrid nanostructures in anodizing aluminum for superior superhydrophobic efficiency. ACS Appl. Mater. Interfaces 2012, 2, 842-848. [CrossRef] [PubMed] 
3. Xu, Q.F.; Wang, J.N.; Sanderson, K.D. A general approach for superhydrophobic coating with strong adhesion strength. J. Mater. Chem. 2010, 28, 5961-5966. [CrossRef]

4. Wang, Z.; Li, Q.; She, Z.; Chen, F.; Li, L. Low-cost and large-scale fabrication method for an environmentally-friendly superhydrophobic coating on magnesium alloy. J. Mater. Chem. 2012, 9, 4097-4105. [CrossRef]

5. Lai, Y.; Tang, Y.; Gong, J.; Gong, D.; Chi, L.; Lin, C.; Chen, Z. Transparent superhydrophobic/superhydrophilic $\mathrm{TiO}_{2}$-based coatings for self-cleaning and anti-fogging. J. Mater. Chem. 2012, 15, 7420-7426. [CrossRef]

6. Farhadi, S.; Farzaneh, M.; Kulinich, S.A. Anti-icing performance of superhydrophobic surfaces. Appl. Surf. Sci. 2011, 14, 6264-6269. [CrossRef]

7. Jung, S.; Dorrestijin, M.; Raps, D.; Das, A.; Megaridis, C.M.; Poulikakos, D. Are superhydrophobic surfaces best for icephobicity? Langmuir 2011, 6, 3059-3066. [CrossRef]

8. Boinovich, L.B.; Gnedenkov, S.V.; Alpysbaeva, D.A.; Egorkin, V.S.; Emelyanenko, A.M.; Sinebryukhov, S.L.; Zaretskaya, A.K. Corrosion resistance of composite coatings on low-carbon steel containing hydrophobic and superhydrophobic layers in combination with oxide sublayers. Corros. Sci. 2012, 55, 238-245. [CrossRef]

9. Jeong, C.; Lee, J.H.; Sheppard, K.; Choi, C.H. Air-impregnated nanoporous anodic aluminum oxide layers for enhancing the corrosion resistance of aluminum. Langmuir 2015, 40, 11040-11050. [CrossRef]

10. Wang, C.; Yao, T.; Wu, J.; Ma, C.; Fan, Z.; Wang, Z.; Cheng, Y.; Lin, Q.; Yang, B. Facile approach in fabricating superhydrophobic and superoleophilic surface for water and oil mixture separation. ACS Appl. Mater. Interfaces 2009, 11, 2613-2617. [CrossRef]

11. Zhou, X.; Zhang, Z.; Xu, X.; Guo, F.; Zhu, X.; Men, X.; Ge, B. Robust and durable superhydrophobic cotton fabrics for oil/water separation. ACS Appl. Mater. Interfaces 2013, 15, 7208-7214. [CrossRef] [PubMed]

12. Zhang, F.; Zhao, L.; Chen, H.; Xu, S.; Evans, D.G.; Duan, X. Corrosion resistance of superhydrophobic layered double hydroxide films on aluminum. Angew. Chem. Int. Edit. 2008, 13, 2466-2469. [CrossRef] [PubMed]

13. Zheng, S.; Li, C.; Fu, Q.; Li, M.; Hu, W.; Wang, W.; Du, M.; Liu, X.; Chen, Z. Fabrication of self-cleaning superhydrophobic surface on aluminum alloys with excellent corrosion resistance. Surf. Coat. Technol. 2015, 276, 341-348. [CrossRef]

14. Zhu, J.; Hsu, C.M.; Yu, Z.; Fan, S.; Cui, Y. Nanodome solar cells with efficient light management and self-cleaning. Nano Lett. 2009, 6, 1979-1984. [CrossRef] [PubMed]

15. Lee, S.B.; Mitchell, D.T.; Trofin, L.; Nevanen, T.K.; Söderlund, H.; Martin, C.R. Antibody-based bio-nanotube membranes for enantiomeric drug separations. Science 2002, 5576, 2198-2200. [CrossRef]

16. Zhang, X.; Shi, F.; Niu, J.; Jiang, Y.; Wang, Z. Superhydrophobic surfaces: from structural control to functional application. J. Mater. Chem. 2008, 6, 621-633. [CrossRef]

17. Davis, J.R.; Davis \& Associates (Eds.) ASM Specialty Handbook: Aluminum and Aluminum Alloys; ASM International: Cleveland, OH, USA, 1993; p. 3.

18. Davis, J.R. (Ed.) Corrosion of Aluminum and Aluminum Alloys; ASM International: Cleveland, OH, USA, 1999; pp. $33-36$.

19. Feng, L.; Che, Y.; Liu, Y.; Qiang, X.; Wang, Y. Fabrication of superhydrophobic aluminium alloy surface with excellent corrosion resistance by a facile and environment-friendly method. Appl. Surf. Sci. 2013, 283, 367-374. [CrossRef]

20. Asmatulu, R.; Ceylan, M.; Nuraje, N. Study of superhydrophobic electrospun nanocomposite fibers for energy systems. Langmuir 2010, 2, 504-507. [CrossRef]

21. Ji, H.; Jeong, C. Study on corrosion and oxide growth behavior of anodized aluminum 5052 Alloy. J. Korean Inst. Surf. Eng. 2018, 6, 372-380.

22. Keller, F.; Hunter, M.S.; Robinson, D.L. Structural features of oxide coatings on aluminum. J. Electrochem. Soc. 1953, 9, 411-419. [CrossRef]

23. Jeong, C.; Choi, C.H. Three-dimensional (3D) anodic aluminum surfaces by modulating electrochemical method. J. Korean Inst. Surf. Eng. 2017, 6, 427-431.

24. Lee, W.; Ji, R.; Gösele, U.; Nielsch, K. Fast fabrication of long-range ordered porous alumina membranes by hard anodization. Nat. Mater. 2006, 9, 741-747. [CrossRef] [PubMed]

25. Alkire, R.C.; Gogotsi, Y.; Simon, P. Nanostructured Materials in Electrochemistry; Eftekhari, A., Ed.; John Wiley \& Sons: Weinheim, Germany, 2008; pp. 9-13.

26. Choi, W.T.; Oh, K.; Singh, P.M.; Breedveld, V.; Hess, D.W. Wettability control of stainless steel surfaces via evolution of intrinsic grain structures. J. Mater. Sci. 2016, 51, 5196-5206. [CrossRef]

27. Masuda, H.; Yada, K.; Osaka, A. Self-ordering of cell configuration of anodic porous alumina with large-size pores in phosphoric acid solution. Jpn. J. Appl. Phys. 1998, 37, L1340-L1342. [CrossRef] 
28. Masuda, H.; Fukuda, K. Ordered metal nanohole arrays made by a two-step replication of honeycomb structures of anodic alumina. Science 1995, 268, 1466-1468. [CrossRef] [PubMed]

29. Lee, W. The anodization of aluminum for nanotechnology applications. JOM 2010, 62, 57-63. [CrossRef]

30. Zhang, J.; Kielbasa, J.E.; Carroll, D.L. Controllable fabrication of porous alumina templates for nanostructures synthesis. Mater. Chem. Phys. 2010, 122, 295-300. [CrossRef]

31. Martín, J.; Martín-González, M.; Fernández, J.F.; Caballero-Calero, O. Ordered three-dimensional interconnected nanoarchitectures in anodic porous alumina. Nat. Commun. 2014, 5, 5130. [CrossRef]

32. O'Sullivan, J.; Wood, G.C. The morphology and mechanism of formation of porous anodic films on aluminium. Proc. R. Soc. Lond. A Math. 1970, 1531, 511-543. [CrossRef]

33. Nielsch, K.; Choi, J.; Schwirn, K.; Wehrspohn, R.B.; Gösele, U. Self-ordering regimes of porous alumina: The 10 porosity rule. Nano Lett. 2002, 7, 677-680. [CrossRef]

34. Chen, C.C.; Chen, J.H.; Chao, C.G. Post-treatment method of producing ordered array of anodic aluminum oxide using general purity commercial (99.7\%) aluminum. Jpn. Appl. Phys. 2005, 44, 1529-1533. [CrossRef]

35. Nishino, T.; Meguro, M.; Nakamae, K.; Matsushita, M.; Ueda, Y. The lowest surface free energy based on $-\mathrm{CF}_{3}$ alignment. Langmuir 1999, 13, 4321-4323. [CrossRef]

36. Miwa, M.; Nakajima, A.; Fujishima, A.; Hashimoto, K.; Watanabe, T. Effects of the surface roughness on sliding angles of water droplets on superhydrophobic surfaces. Langmuir 2000, 13, 5754-5760. [CrossRef]

37. Cortese, B.; D'Amone, S.; Manca, M.; Viola, I.; Cingolani, R.; Gigli, G. Superhydrophobicity due to the hierarchical scale roughness of PDMS surfaces. Langmuir 2008, 6, 2712-2718. [CrossRef] [PubMed]

38. Cassie, A.B.D.; Baxter, S. Wettability of porous surfaces. Trans. Faraday Soc. 1944, 40, 546-551. [CrossRef]

(C) 2019 by the authors. Licensee MDPI, Basel, Switzerland. This article is an open access article distributed under the terms and conditions of the Creative Commons Attribution (CC BY) license (http://creativecommons.org/licenses/by/4.0/). 